Research Article

\title{
Finite Element Analysis of Stress on Cross-Wavy Primary Surface Recuperator Based on Thermal-Structural Coupling Model
}

\author{
Xiaohong Gui $\left(\mathbb{D},{ }^{1}\right.$ Xiange Song, ${ }^{2}$ Haiwen Gong, ${ }^{1}$ Dianbao Yao, ${ }^{1}$ Ruogu Chen, \\ and Guang $\mathrm{Xu}^{3}$ \\ ${ }^{1}$ China University of Mining and Technology, Beijing 100083, China \\ ${ }^{2}$ Beijing International Studies University, Beijing 100024, China \\ ${ }^{3}$ Western Australian School of Mines, Curtin University, Kalgoorlie, WA 6430, Australia \\ Correspondence should be addressed to Xiaohong Gui; gxhbox@sina.com
}

Received 26 June 2020; Revised 22 October 2020; Accepted 1 February 2021; Published 11 February 2021

Academic Editor: Marco Cannas

Copyright $($ C 2021 Xiaohong Gui et al. This is an open access article distributed under the Creative Commons Attribution License, which permits unrestricted use, distribution, and reproduction in any medium, provided the original work is properly cited.

In order to study the stress, strain and deformation of the recuperator, the thermal-structural coupling finite element analysis model of cross-wavy primary surface recuperator of gas microturbine was established. The stress of cross-wavy primary surface recuperator after operation under design conditions was analyzed by finite element method. The reliability of the material selected for the recuperator was verified, and the effects of pressure ratio and gas inlet temperature on stress and displacement of the recuperator were analyzed. The research results show that the maximum stress and strain on the gas outlet side of the recuperator are higher than the maximum stress and strain on the gas inlet side when only pressure is considered, and the result is the opposite when pressure and thermal stress are considered. The air passage of the recuperator deforms to the side of the gas passage, the air passage becomes larger, and the gas passage shrinks. With the increase of pressure ratio between air side and gas side, the maximum stress of recuperator passage also increases. When the pressure ratio increases to 8.4, the strength limit of the heat exchange fin material is reached. When the gas and air outlet temperatures remain unchanged and the thermal ratio decreases, as the gas inlet temperature increases, the maximum stress increases. For every $50 \mathrm{~K}$ increase in the gas inlet temperature, the maximum stress of the recuperator increases by about $2.3 \mathrm{MPa}$. The research results can be used to guide the designing and optimization of recuperator.

\section{Introduction}

The microturbine is a new type of engine. In recent years, it has developed rapidly in the field of distributed generation/ energy systems. The adoption of efficient and compact heat exchanger technology is one of the keys to its successful application. Based on the compactness of the gas turbine, the designer must design a compact recuperator that is the smallest in volume and mass, the lowest in cost, and easy to automate mass production. Figure 1 shows the schematic diagram of the microturbine with recuperator, which is mainly composed of centrifugal compressor, centripetal turbine, combustion chamber, and recuperator. After the air is compressed by the compressor, it enters the recuperator, raises the temperature, then enters the combustion chamber, mixes with the fuel and burns, enters the turbine, discharges in the turbine, and discharges the flue gas with higher temperature and then enters the recuperator. It is used to heat the cold air from the compressor to further improve the system efficiency. Therefore, the role of recuperator is to use the waste heat in the gas turbine exhaust to heat the compressed air to save part of the fuel, so that the exhaust gas temperature is reduced to recover the waste heat, thereby improving the efficiency of the whole machine.

For saving the fuel and increasing the efficiency of gas turbine cycle, recuperator is used to warm up the air entering the combustion of gas turbine by absorbing the heat of exhaust in recuperation cycle. It makes the efficiency of cycle $10 \%$ higher and even more by using recuperated cycle. Recuperator, as the key part in recuperated cycle, plays an 


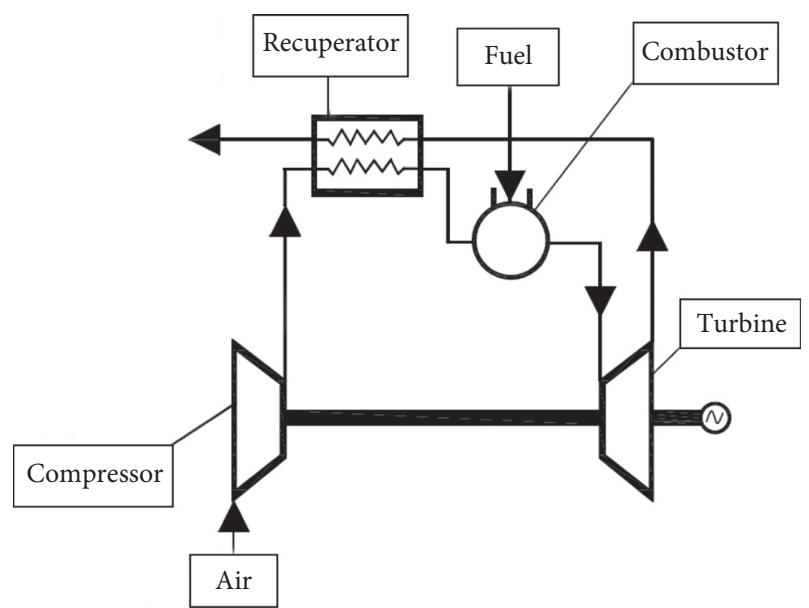

FIgURE 1: Microturbine plant with recuperator.

important role in the increase of the efficiency of gas turbine. It must be a kind of recuperator, which has a small volume, light weight, high recuperated effectiveness, and high reliability for using on gas microturbine. Investigation indicates that the cross-wavy primary surface recuperator (CWPSR) can satisfy these demands, so it is the preferred structure of recuperator of microturbine.

Under the condition of half-wall thickness and multiperiod boundary conditions, Xi et al. [1] established a threedimensional fluid-solid coupling heat transfer model considering the interaction between high-temperature hot gas and compressed cold air and predicted the flow and heat transfer in shear wave channel. By comparing the heat transfer and pressure loss of five configurations, the effecting law of geometrical parameters is revealed.

Cai et al. [2] introduced a computational model of heat transfer and pressure drop established for the design optimization of the annular involute-profile cross-wavy primary surface recuperator (CWPSR) in microturbine. The genetic algorithm method is employed to solve the optimization problem of annular CWPS recuperator with multiple design variables.

Wu et al. [3] conducted a numerical simulation to study the flow and heat transfer in the CW primary surface channel. The CW primary surface channels are set up in the 3D numerical simulation model for different configurations and generating the grid. Then, the flow and heat transfer are simulated in these models when the Reynolds number is low $(\operatorname{Re}=50 \sim 600)$, and the periodic boundary condition is used for the boundary. The numerical study of the fluid flow and heat transfer characteristics for the two different configurations shows that the average Nusselt number increases as Reynolds number increases, while the friction factor decreases with the increase of Reynolds number. The rectangular cross-section has the best comprehensive performance among the two configurations.

$\mathrm{Ma}$ et al. [4] performed naphthalene sublimation experiments for cross-wavy channels in a wind tunnel. The experimental results indicate that the entrance region has a small effect on the unit-averaged heat transfer coefficient of whole cross-wavy channels. Correlations of Nusselt number and friction factor in the cross-wavy channel are obtained. Based on the similarity rules, five cross-wavy channels with similar structures but different equivalent diameters are further investigated by numerical simulations. The numerical results indicate that the cross-wavy channels with similar structures but different equivalent diameters have similar a thermal-hydraulic performance in the studied Reynolds number range.

Maghsoudi et al. [5] aims to perform a comprehensive thermoeconomic analysis, optimization, and ranking of cross- and counterflow plate-fin recuperators employing rectangular, triangular, offset strip, and louver fins. The analysis is mainly conducted for two recuperator structures: (i) fins' configurations on both hot and cold sides are the same; (ii) fins on the hot and cold sides are dissimilar in configuration. Considering the effective practical optimization constraints and design parameters, nondominated sorting genetic algorithm (NSGA-II) is used to maximize the recuperator effectiveness and minimize its total cost, simultaneously. Pareto-optimal fronts are presented to specify the desirable recuperator designs satisfying the constraints. Afterwards, in order to accurately and reliably rank the optimal designs based on significant factors including recuperator effectiveness, total cost, volume, mass and pressure drop, data envelopment analysis (DEA) model is utilized.

Xiao et al. [6] aims to provide a comprehensive understanding about recuperators, covering fundamental principles (types, material selection, and manufacturing), operating characteristics (heat transfer and pressure loss), optimization methods, and research hotspots and suggestions. It is revealed that primary surface recuperator is prior to plate-fin and tubular ones. Ceramic recuperators outperform metallic recuperators in terms of high-temperature mechanical and corrosion properties, being expected to facilitate the overall efficiency approaching 40\%. Heat transfer and pressure drop characteristics are crucial for designing a desired recuperator, and more experimental and simulation studies are necessary to obtain accurate empirical correlations for optimizing configurations of heat transfer surfaces with high ratios of Nusselt number to friction factor. Optimization methods are summarized and discussed, considering complicated relationships among pressure loss, heat transfer effectiveness, compactness, and cost, and it is noted that multiobjective optimization methods are worthy of attention. Generally, a metallic cost-effective primary surface recuperator with high effectiveness and low pressure drop is a currently optimal option for a gas microturbine of an efficiency similar to $30 \%$, while a ceramic recuperator is suggested for a high efficiency gas microturbine (e.g., 40\%).

The distributed gas turbine power generation device is simple and flexible. It can not only provide different levels of power but also provide good emergency power generation equipment. Through the utilization of waste heat of gas, the comprehensive utilization rate of fuel can be further improved, and its comprehensive benefit is not lower than or even higher than the electricity consumption of unified grid [7]. The emergence of microturbine provides safe and reliable power and energy for the decentralization of office and 
miniaturization of production in order to avoid the defects of unified power grid and meet the needs of the deepening reform of the power industry. Some people call it the power illusion of the 21st century, and it has a broad market prospect.

In order to increase the efficiency of gas microturbine to $30 \%$, the key is to adopt a regenerative cycle. The recuperator has the characteristics of high heat transfer efficiency, low pressure loss, small size, and light weight. At the same time, it should also have high operational reliability and durability. In the high temperature and high pressure working environment, there will be a great stress and strain in the recuperator passage, and the gas passage will be deformed, which will affect the flow of air and even lead to the rupture of heat exchanger unit sheet and abandonment of recuperator. Therefore, it is necessary to analyze the stress, strain, and deformation of recuperator.

\section{Finite Element Analysis of Stress, Strain, and Deformation of Microturbine Recuperator [8-10]}

2.1. Physical Model and Boundary Conditions. The recuperator is composed of several heat exchange units, each of which includes a heat exchange plate on the cross-wavy primary surface, welded together to form an air channel, between which is a gas channel, as shown in Figure 2. The shape of each cross-section of the element is the same, and the air and gas passage are arranged alternately. Therefore, a two-dimensional model can be established to calculate the stress and strain [11].

The material of heat exchanger is $0 \mathrm{Cr} 17 \mathrm{Ni} 12 \mathrm{Mo} 2$. The geometric parameters are pitch $P=1.8 \mathrm{~mm}$, height $H=1.8 \mathrm{~mm}$, gas channel diameter $W_{\text {gas }}=1.1 \mathrm{~mm}$, air channel diameter $W_{\text {air }}=0.7 \mathrm{~mm}$, and wall thickness $0.1 \mathrm{~mm}$.

Some assumptions are made as follows.

(1) The flow field inside the recuperator is steady; that is, the temperature of the recuperator does not change with time. In practice, as the recuperator works at a high temperature for a long period of time, it is a long-term operating part, so the temperature of the recuperator will fluctuate when it works.

(2) Thermal stress has no effect on creep. In fact, when the recuperator operates at a high temperature for a long time, the thermal stress generated by the heating will continue to attenuate during the creep process. When the creep reaches the stable stage, the thermal stress will approach zero.

The recuperator gas and air channels are countercurrent arrangement. According to the simulation results of our group [12], the air inlet pressure of the recuperator is $382428 \mathrm{~Pa}$, the air inlet temperature is $463 \mathrm{~K}$, the air outlet pressure is $374779 \mathrm{~Pa}$, the air outlet temperature is $873 \mathrm{~K}$, the gas inlet pressure of the recuperator is $105547 \mathrm{~Pa}$, the gas inlet temperature is $928 \mathrm{~K}$, the gas outlet pressure is $101325 \mathrm{~Pa}$, and the gas outlet temperature is $529 \mathrm{~K}$. Since the recuperator works at high temperature for a long time and is

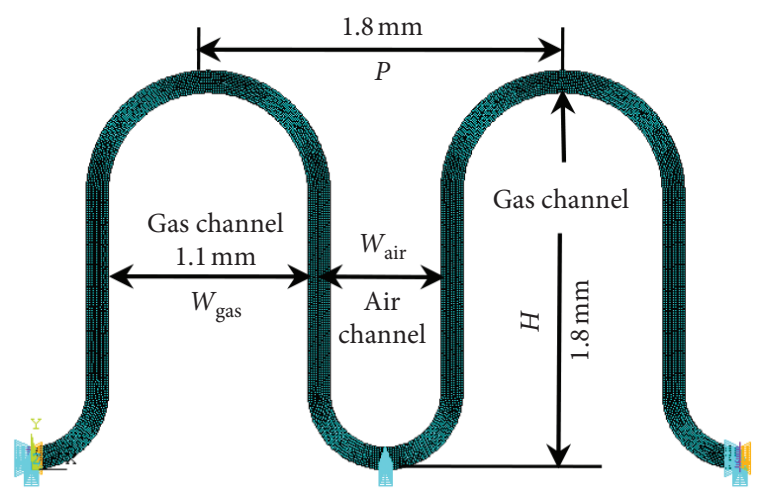

Figure 2: Physical model and constraint load.

a long-term operating component, the temperature fluctuation during the recuperator operation is not considered in the calculation, and the flow field inside the recuperator is treated as a steady state; that is, the recuperator temperature does not change with time.

Periodic boundary conditions are applied to the left and right sections during the calculation. The finite element model and constraint loads are shown in Figure 2.

2.2. Mathematical Model [13]. Thermal stress problem is actually a coupling problem between two physical fields of heat and stress. There are two analytical methods, the direct method and the indirect method. The direct method refers to the direct use of coupled elements with temperature and displacement degrees of freedom. The direct method means that the results of thermal analysis and structural stress analysis are obtained by using the coupling element with temperature and displacement degrees of freedom. The indirect principle refers to carrying out thermal analysis first, then applying the calculated node temperature as a temperature load to the structural stress analysis, and obtaining the stress analysis results.

Direct method and indirect method have their own advantages and disadvantages. As for the direct method, it has two advantages: (1) it uses one element type to solve two physical problems and can achieve the real coupling between thermal problems and structural phenomena; (2) as the interaction of coupled fields is highly nonlinear, the direct method is preferred and it is the best method when the coupling formula is used for a single solution. However, it also has some disadvantages: (1) the direct coupling analysis is usually nonlinear because the equilibrium state must meet several criteria; (2) the more the degrees of freedom at each node, the greater the matrix equation, the greater the computational effort, and the more the time it takes. There are three advantages of indirect method: (1) it can use all the functions of thermal analysis and structural analysis and cannot require a special cell type, and also, it is more efficient than direct coupling; (2) in practical problems, this approach is more convenient than the direct coupling because the analysis uses a single field element and does not require multiple iterations; (3) for coupling cases that are not highly nonlinear, the indirect method is more efficient and flexible 
because the two analyses can be performed independently of each other. Furthermore, the indirect method also has disadvantages. That is, the steps of the indirect method are more complex than those of the direct method. In this study, in order to improve efficiency and save calculation time, indirect method is adopted.

2.2.1. The Heat Conduction Equation of the Recuperator Core. Since the recuperator is a part of long-term operation (the designed operation time is $40000 \mathrm{~h}$ ), the heat transfer reaches a stable state quickly during operation, which can be solved as a steady-state problem. The differential equation of heat conduction is

$$
\frac{\partial T}{\partial x^{2}}+\frac{\partial T}{\partial y^{2}}=0
$$

Convective boundary conditions are satisfied:

$$
-\lambda\left(\frac{\partial T}{\partial n}\right)_{w}=h\left(T_{w}-T_{f}\right) .
$$

Adiabatic boundary conditions are met:

$$
\frac{\partial T}{\partial n}=0
$$

In the aforementioned formula, $T_{w}$ is the wall temperature, $\mathrm{K} ; T_{f}$ is the fluid temperature, $\mathrm{K} ; \lambda$ is the thermal conductivity of the material, $\mathrm{W} / \mathrm{m} \cdot \mathrm{K}$.

\subsubsection{Thermoelastic Mechanics Plane Stress Equation.} For the thermoelastic plane stress problem, $\sigma_{z}=0, \tau_{x z}=\tau_{y z}=0, \gamma_{x z}=\gamma_{y z}=0$, at this point, the equilibrium, constitutive, and strain coordination equations can be simplified as follows:

(1) The balance equation is as follows:

$$
\left.\begin{array}{c}
\frac{\partial \sigma_{x}}{\partial x}+\frac{\partial \tau_{y x}}{\partial y}=0 \\
\frac{\partial \tau_{x y}}{\partial x}+\frac{\partial \sigma_{y}}{\partial y}=0
\end{array}\right\}
$$

(2) The constitutive equation is as follows:

$$
\left.\begin{array}{l}
\sigma_{x}=\frac{E}{1-\mu^{2}}\left[\varepsilon_{x}+\mu \varepsilon_{y}-(1+\mu) \alpha \Delta T\right] \\
\sigma_{y}=\frac{E}{1-\mu^{2}}\left[\varepsilon_{y}+\mu \varepsilon_{x}-(1+\mu) \alpha \Delta T\right] \\
\tau_{x y}=\frac{E}{2(1+\mu)} \gamma_{x y}
\end{array}\right\} .
$$

(3) The strain coordination equation is as follows:

$$
\frac{\partial^{2} \varepsilon_{x}}{\partial y^{2}}+\frac{\partial^{2} \varepsilon_{y}}{\partial x^{2}}=\frac{\partial^{2} \gamma_{x y}}{\partial x \partial y},
$$

where

$$
\begin{gathered}
\varepsilon_{x}=\frac{\partial u}{\partial x}, \\
\varepsilon_{y}=\frac{\partial v}{\partial y}, \\
\gamma_{x y}=\frac{\partial v}{\partial x}+\frac{\partial u}{\partial y} .
\end{gathered}
$$

The static boundary conditions are also simplified as

$$
\left.\begin{array}{l}
\sigma_{x} l_{1}+\tau_{x y} l_{2}=0 \\
\tau_{y x} l_{1}+\sigma_{y} l_{2}=0
\end{array}\right\} .
$$

According to the aforementioned equations and combined with displacement boundary conditions, the displacement $u$ and $v$ can be obtained, and then the stress solution can be obtained by substituting them into (5).

2.3. Grid Division. Generally, there are several types of grids in finite element analysis, such as triangular mesh, quadrilateral mesh, and hexahedron mesh. Triangular and quadrilateral grids are used for 2D model, while hexahedron mesh is used for $3 \mathrm{D}$ model. The calculation accuracy of quadrilateral grid is higher than that of triangular grid, so the quadrilateral grid is recommended. In this study, the computational model is two-dimensional. Therefore, quadrilateral grid is adopted, with 9444 cells and 10317 nodes. Two sets of grids are used to verify the grid independence. Grid 1 has 5490 elements and 5997 nodes, and the maximum stress is $78.9 \mathrm{MPa}$. The maximum stress is 78.2 MPa with 9444 elements and 19493 nodes in grid 2. The stress error of two sets of grids is less than $0.89 \%$. Grid 2 is selected as the calculation grid.

2.4. Discretization. Partial differential equations (PDEs) are the basis of mathematical modeling for physics and engineering problems. In order to analyze the PDE of a real system to an acceptable level, discretization is needed. When solving engineering problems, finite element method (FEM) is one of the most commonly used discretization methods, which can be used to calculate the approximate value of the real solution of partial differential equations. However, other methods can also be used for discretization, for example, mesh-free methods and isogeometric analysis (IGA), whose basic idea is to approximate the solution of partial differential equation by using functions with desirable properties. Samaniego et al. [14] studied deep neural networks (DNNs) as an alternative to approximations and found that they have good results in areas such as visual recognition. Anitescu et al. [15] proposed the method of artificial neural network and adaptive matching strategy to solve partial differential equations (PDEs). This method uses only scattered point sets 
in the training and evaluation sets and is completely meshless. It can improve the robustness of neural network approximation and save a lot of computing resources, especially when the solution is not smooth.

\section{Calculation Results and Analysis}

3.1. Comparisons and Analysis of Stress, Strain, and Deformation between the Inlet and Outlet in Recuperator Channel without considering Thermal Stress. Figure 3 shows the stress distribution on the side of air inlet and gas outlet when the thermal stress is not considered but pressure is taken into account. The maximum stress is $60.8 \mathrm{MPa}$. Figure 4 shows the stress distribution at the air outlet and gas inlet side, with the maximum stress of $58.3 \mathrm{MPa}$. Figure 5 shows the strain distribution on the side of air inlet and gas outlet, whose maximum strain is $0.292 \mathrm{e}-3$. Figure 6 shows the lateral strain distribution of air outlet and gas inlet, whose maximum strain is $0.279 \mathrm{e}-3$; Figure 7 shows the deformation distribution at the air inlet and gas outlet side, with the maximum deformation of $0.550 \mathrm{e}-3 \mathrm{~mm}$. Figure 8 shows the deformation distribution at the air outlet and gas inlet side, with the maximum deformation of $0.526 \mathrm{e}-3 \mathrm{~mm}$. It can be seen that the maximum stress, strain, and deformation of gas outlet and air inlet side in recuperator are larger than those of gas inlet and air outlet side when thermal stress is not considered and pressure is only taken into account. The reason is that the air inlet pressure and gas outlet pressure of the recuperator are $382428 \mathrm{~Pa}$ and $101325 \mathrm{~Pa}$, respectively. The pressure ratio is $3.77: 1$. The air outlet pressure and gas inlet pressure of the recuperator are $374779 \mathrm{~Pa}$ and $105547 \mathrm{~Pa}$, respectively. With the increase of pressure ratio between air side and gas side, the maximum stress, strain, and deformation increase. The recuperator is arranged counterflow, so the maximum stress, strain, and deformation occur at the air inlet and gas outlet side. In addition, it can be seen from the figure that the air passage deforms to the side of the gas passage, the air passage becomes larger, the gas passage decreases, and the maximum deformation is smaller, which is in the order of $10^{-7} \mathrm{~m}$.

3.2. Comparison and Analysis of Stress, Strain, and Deformation between the Inlet and Outlet in Recuperator Channel When Thermal Stress Is Taken into Account. Figure 9 shows the stress distribution at the air inlet and gas outlet side when thermal stress is taken into account. The maximum stress is 66.4 MPa. Figure 10 shows the

stress distribution at the air outlet and gas inlet side, and its maximum stress is $78.2 \mathrm{MPa}$. Figure 11 shows the strain distribution on the side of air inlet and gas outlet, whose maximum strain is $0.336 \mathrm{e}-3$; Figure 12 shows the lateral strain distribution of air outlet and gas inlet, whose maximum strain is $0.478 \mathrm{e}-3$; Figure 13 shows the deformation distribution at the air inlet and gas outlet side, and its maximum deformation is $0.562 \mathrm{e}-3 \mathrm{~mm}$. Figure 14 shows the deformation distribution at the air outlet and gas inlet side, and its maximum deformation is $0.656 \mathrm{e}-3 \mathrm{~mm}$. It can be seen that when thermal stress is taken into account, the

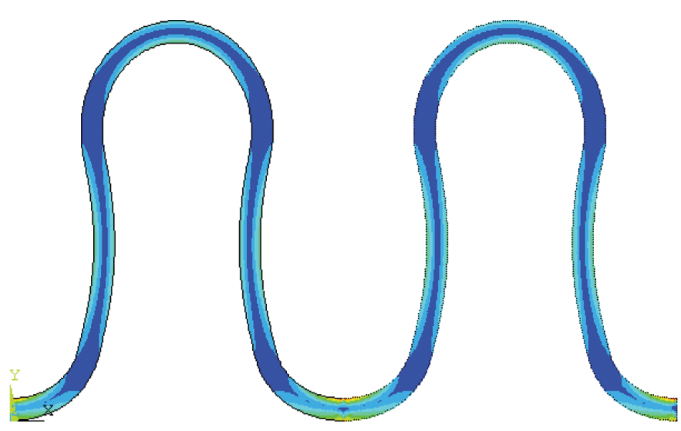

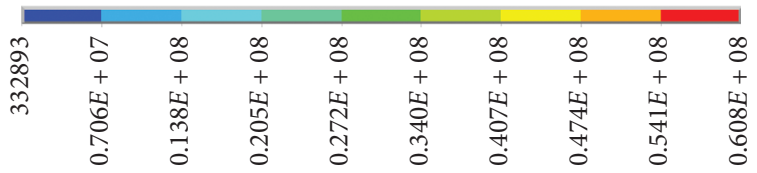

FIgURE 3: Stress distribution at air inlet and gas outlet side without considering thermal stress $(\mathrm{Pa})$.

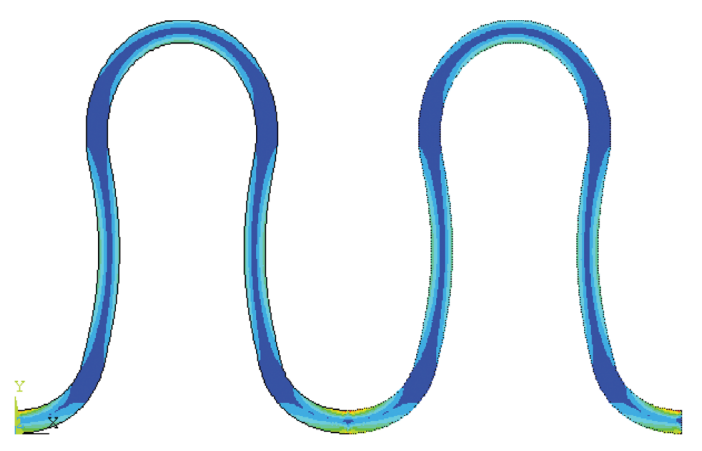

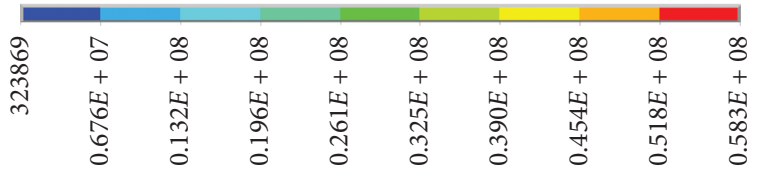

FIGURE 4: Stress distribution at air outlet and gas inlet side without considering thermal stress $(\mathrm{Pa})$.

maximum stress, strain, and deformation of air inlet and gas outlet side of recuperator are less than those of air outlet and gas inlet side. The reason is that the recuperator adopts countercurrent arrangement. The gas inlet temperature of the recuperator is $928 \mathrm{~K}$, the air outlet temperature is $873 \mathrm{~K}$, the gas outlet temperature is $529 \mathrm{~K}$, and the air inlet temperature is $463 \mathrm{~K}$. The gas inlet temperature is much higher than the gas outlet temperature, and the air outlet temperature is much higher than the air inlet temperature. Although the pressure ratio between air outlet and gas inlet in recuperator is less than that between air inlet and gas outlet in recuperator, the maximum stress, strain, and deformation of air outlet and gas inlet are obviously increased under the coupling effect of pressure and temperature. It can be seen that the thermal stress caused by thermal expansion caused by temperature increase is significant, and enough attention must be paid to it. By Comparing Figure 3 with 


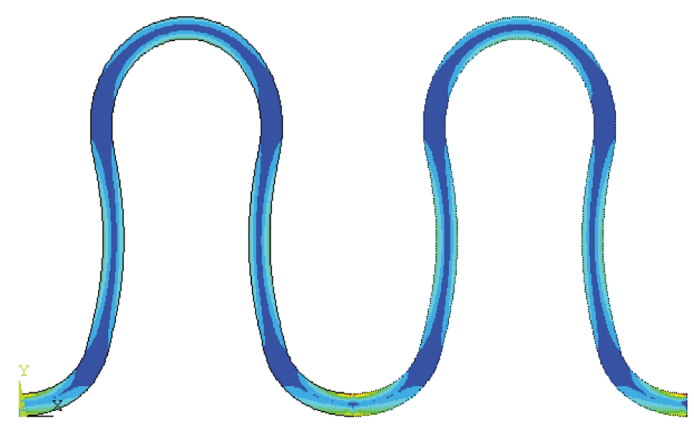

\begin{tabular}{|c|c|c|c|c|c|c|c|c|c|}
\hline & & & & & & & & & \\
\hline 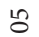 & J & J & J & $\stackrel{m}{0}$ & $\tilde{o}$ & $\stackrel{m}{0}$ & $\stackrel{0}{0}$ & $\stackrel{n}{0}$ & $\stackrel{n}{0}$ \\
\hline 1 & 1 & 1 & 1 & 1 & 1 & 1 & 1 & 1 & 1 \\
\hline 넘 & 딤 & 게 & $\mathrm{y}$ & 四 & 닝 & 님 & 디 & 딩 & II \\
\hline$\underline{\underline{I}}$ & m. & రి & నో & $\vec{m}$ & ชூ & $\stackrel{2}{2}$ & $\approx$ & రె & \\
\hline & 0 & $0^{\circ}$ & 0 & 0 & 0 & 0 & 0 & 0 & P \\
\hline
\end{tabular}

FIGURE 5: Strain distribution at air inlet and gas outlet side without considering thermal stress $(\mathrm{Pa})$.

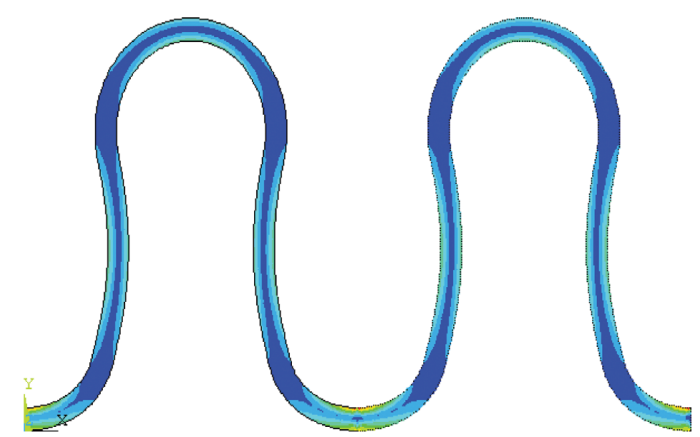

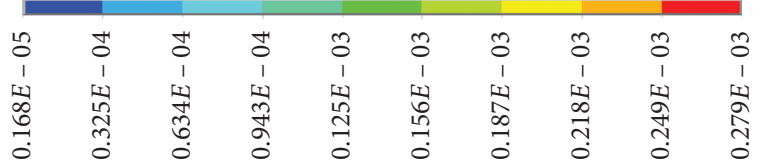

FIGURE 6: Strain distribution at air outlet and gas inlet side without considering thermal stress $(\mathrm{Pa})$.

Figure 9, comparing Figure 4 with Figure 10, comparing Figure 5 with Figure 11, comparing Figure 6 with Figure 12, comparing Figure 7 with Figure 13, comparing Figure 8 with Figure 14, it can be seen that when thermal stress is taken into account, the stress, strain, and deformation at inlet and outlet of recuperative passage increase obviously under the coupling action of pressure and temperature. As the material of the heat exchanger is $0 \mathrm{Cr} 17 \mathrm{Ni12Mo2}$, the strength limit of $0 \mathrm{Cr} 17 \mathrm{Ni} 12 \mathrm{Mo} 2$ is $170 \mathrm{MPa}$, which is greater than the stress value of $78.2 \mathrm{MPa}$. According to the literature [16], it can be seen the strength of the $0 \mathrm{Cr} 17 \mathrm{Ni12Mo2}$ limit is $170 \mathrm{MPa}$, which is greater than the thermal stress value of $78.2 \mathrm{MPa}$. Therefore, the designed recuperator is safe and reliable in strength.

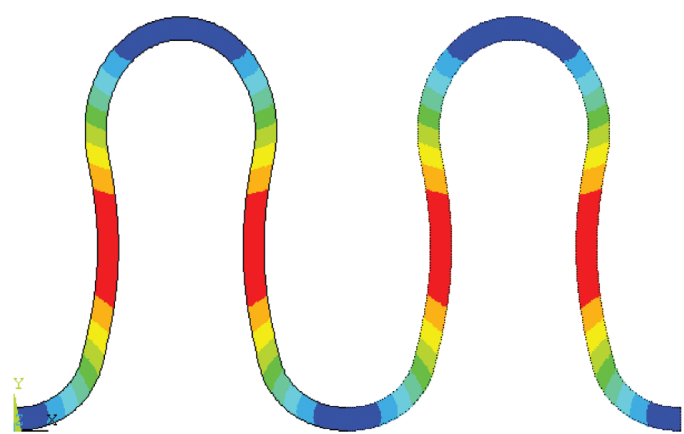

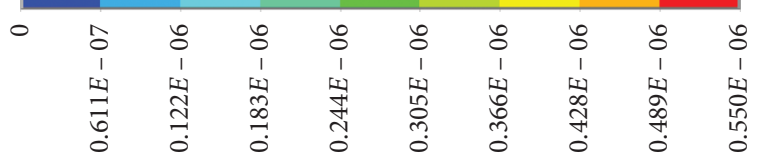

FIgURe 7: Deformation distribution at air inlet and gas outlet side without considering thermal stress $(\mathrm{m})$.
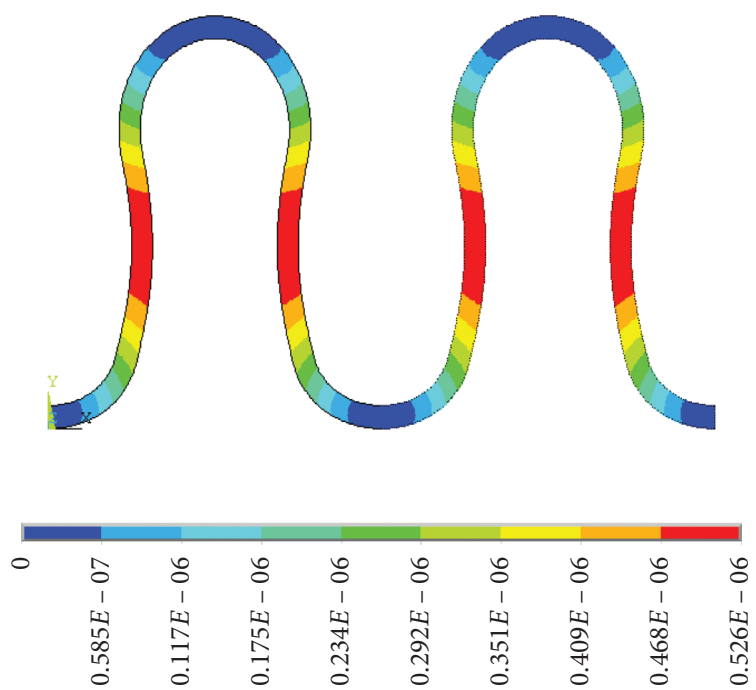

Figure 8: Deformation distribution at air outlet and gas inlet side without considering thermal stress $(\mathrm{m})$.

3.3. Effect of Pressure Ratio on Stress and Deformation of Recuperator. Figure 15 shows that the maximum stress and deformation of gas inlet and air outlet vary with the pressure ratio between air side and gas side, while the temperature and pressure of the gas inlet and the temperature of air outlet remain unchanged. It can be seen that, with the increase of pressure ratio between air side and gas side, the maximum stress and maximum deformation of recuperator also increase. When the pressure ratio increases to 8.4, the maximum stress of the recuperator reaches $170 \mathrm{MPa}$ and reaches the strength limit of the heat exchanger material $0 \mathrm{Cr} 17 \mathrm{Ni} 12 \mathrm{Mo} 2$. When the pressure ratio increases to 8.5 , 


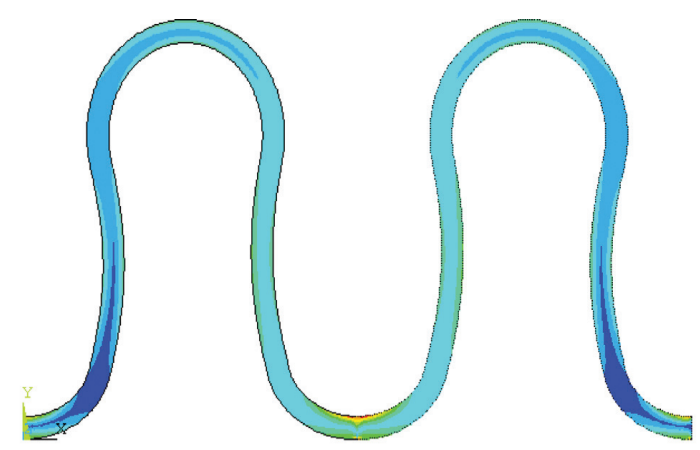

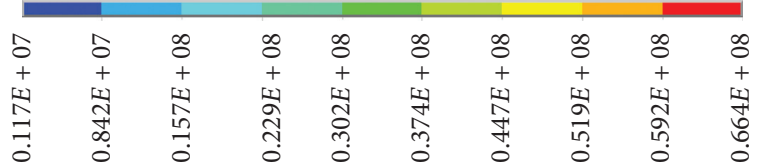

Figure 9: Stress distribution at air inlet and gas outlet side considering thermal stress $(\mathrm{Pa})$.

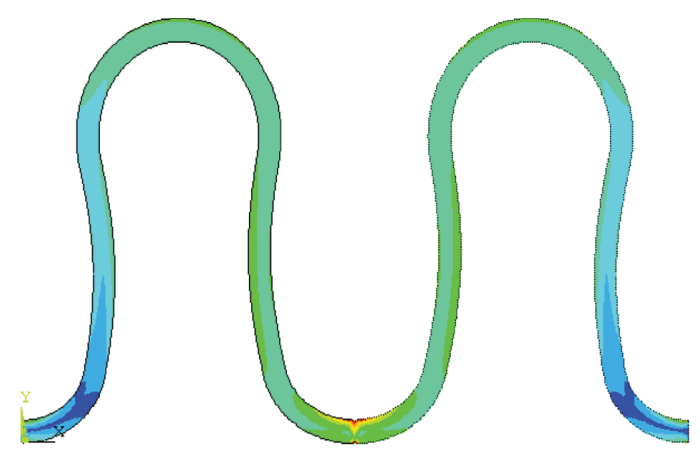

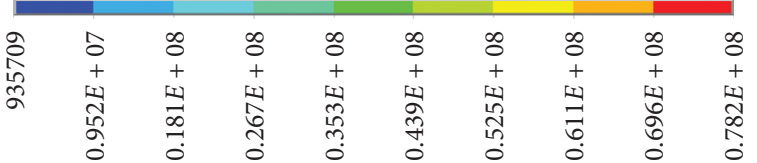

Figure 10: Stress distribution at air outlet and gas inlet side considering thermal stress $(\mathrm{Pa})$.

the maximum stress of the recuperator increases to $172 \mathrm{MPa}$, which exceeds the strength limit of the heat exchanger material $0 \mathrm{Cr} 17 \mathrm{Ni} 12 \mathrm{Mo} 2$. Therefore, when designing a recuperator, in order to ensure its safety and reliability, the pressure ratio between air side and gas side should not exceed 8.4.

\subsection{Effect of Gas Inlet Temperature on Stress and Deformation} of Recuperator. According to the literature [17], with the increase of gas inlet temperature, the gas outlet temperature changes a little, and the thermal ratio decreases gradually. According to this idea, the stress finite element analysis of gas inlet and air outlet in recuperator is carried out; that is, only the gas inlet temperature is changed, while the gas outlet temperature and air outlet temperature remain

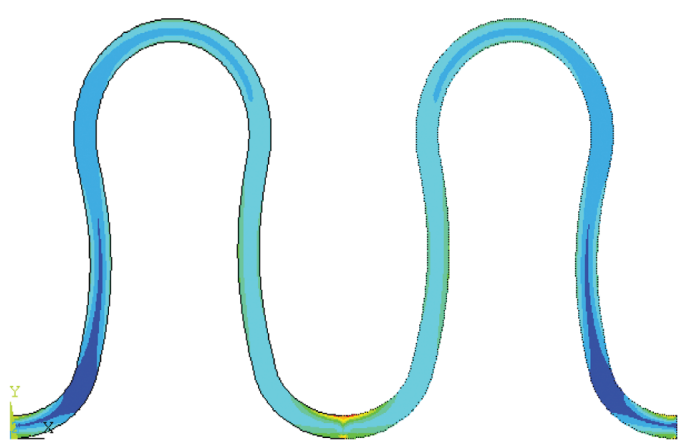

\begin{tabular}{|c|c|c|c|c|c|c|c|c|}
\hline ㄴ? & J & t' & m & m & m & 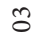 & $\tilde{0}$ & $\tilde{0}$ \\
\hline 1 & 1 & 1 & 1 & 1 & 1 & 1 & 1 & 1 \\
\hline 밈 & 서 & 믹 & 圆 & 긴 & 석 & $y$ & 미 & 桴 \\
\hline భ & I & r. & $\exists$ & $\stackrel{+}{+}$ & $\infty$ & 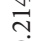 & $\stackrel{+}{+}$ & 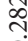 \\
\hline & 0 & $0^{\circ}$ & $\dot{0}$ & 0 & 0 & 0 & & \\
\hline
\end{tabular}

FIgURE 11: Strain distribution at air inlet and gas outlet side considering thermal stress.

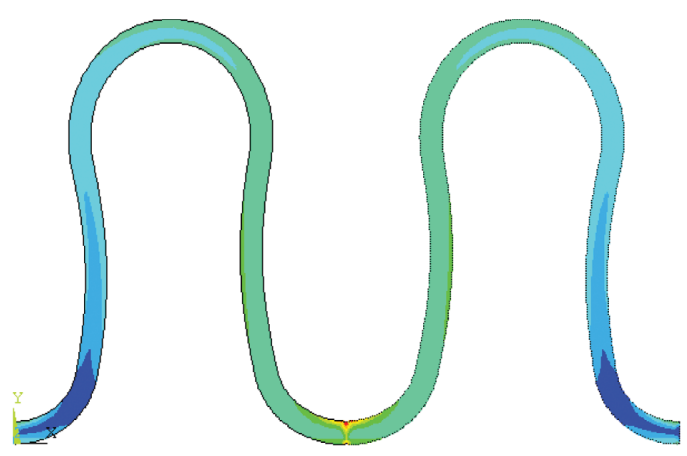

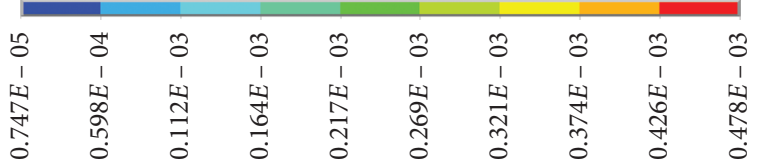

FIgURE 12: Strain distribution at air outlet and gas inlet side considering thermal stress.

unchanged. Figure 16 shows that the maximum stress which occurs in the trough of air passage and maximum deformation of the recuperator vary with the temperature of gas inlet, while the thermal ratio remains unchanged. It can be seen that, with the increase of gas inlet temperature, the maximum stress increases. For every $50 \mathrm{~K}$ increase of gas inlet temperature, the maximum stress of recuperator increases by $2.3 \mathrm{MPa}$, and the maximum deformation increases by about $0.025 \mu \mathrm{m}$. In this paper, $0 \mathrm{Cr} 17 \mathrm{Ni} 12 \mathrm{Mo} 2$ is chosen as isotropic material for heat exchanger sheet, which satisfies Hooke's theorem, i.e., the relationship between stress and deformation is linear. It can also be seen from the figure that there is a linear relationship between maximum stress and maximum deformation.

Figure 17 shows the variation trend of the maximum stress calculated with the gas inlet temperature in [13]. It can 


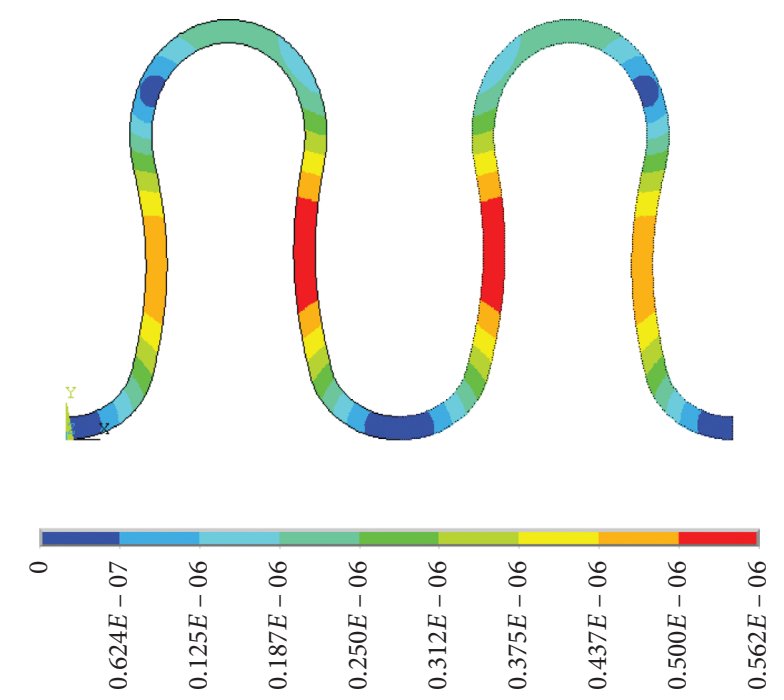

FIGURE 13: Deformation distribution at air inlet and gas outlet side considering thermal stress $(\mathrm{m})$.

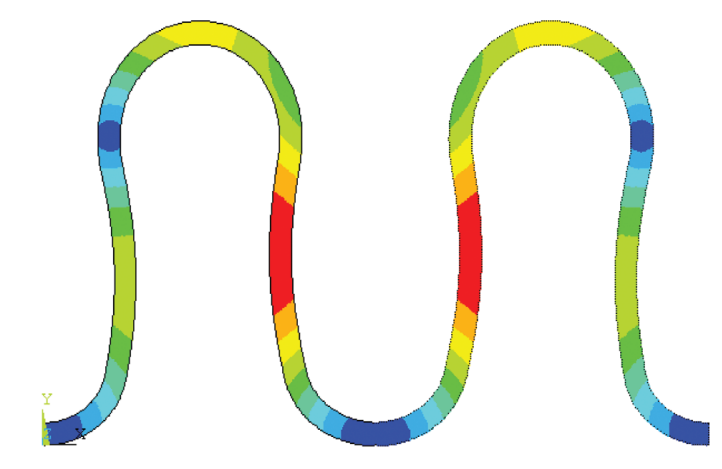

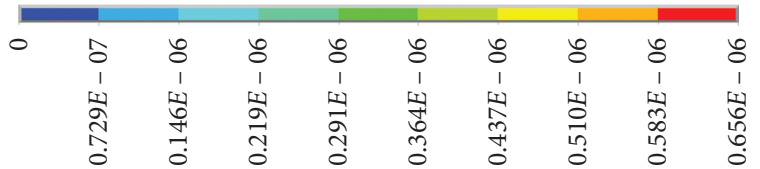

FIGURE 14: Deformation distribution at air outlet and gas inlet side considering thermal stress $(\mathrm{m})$.

be seen that the maximum stress which occurs in the trough of air passage increases with the increase of the gas inlet temperature and shows a linear change trend. As the temperature rises by $50 \mathrm{~K}$, the maximum stress increases by $6 \mathrm{MPa}$, which is higher than the results calculated in this paper. The reason is that the thermal ratio is set to the same. With the increase of gas inlet temperature, the gas outlet temperature and air outlet temperature also increase, and the maximum stress increases rapidly. In fact, according to the experimental research in the literature [17], with the increase of gas inlet temperature, the gas outlet temperature does not change much, and the thermal ratio decreases gradually. Through the aforementioned comparison, it is further explained that the increase of thermal stress caused by the increase of temperature is significant and must be paid enough attention.

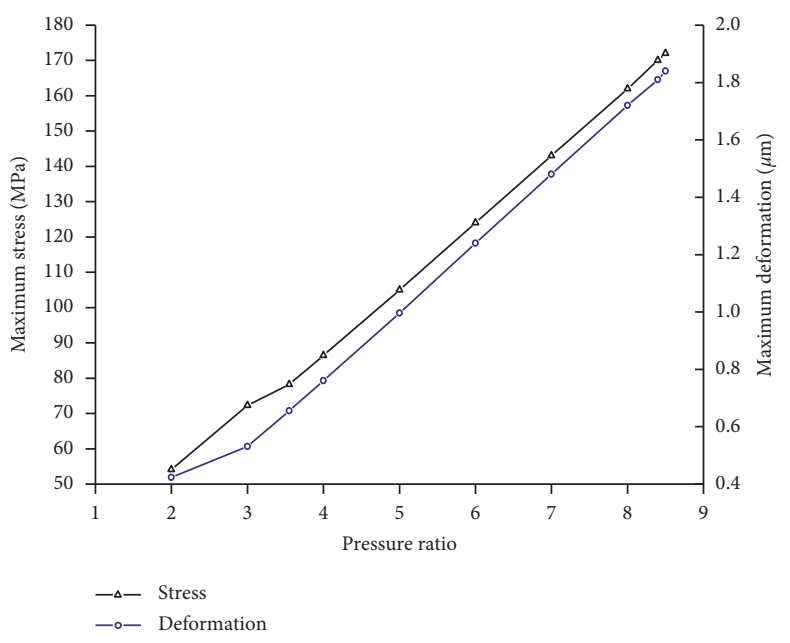

FIGURE 15: Variation of maximum stress and maximum deformation with pressure ratio in recuperator.

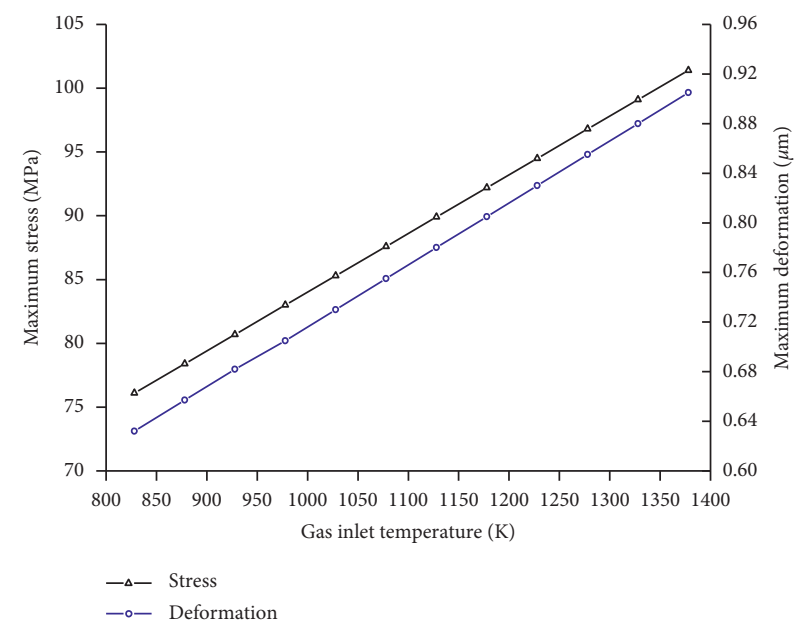

FIGURE 16: Maximum stress and maximum deformation vary with gas inlet temperature in recuperator.

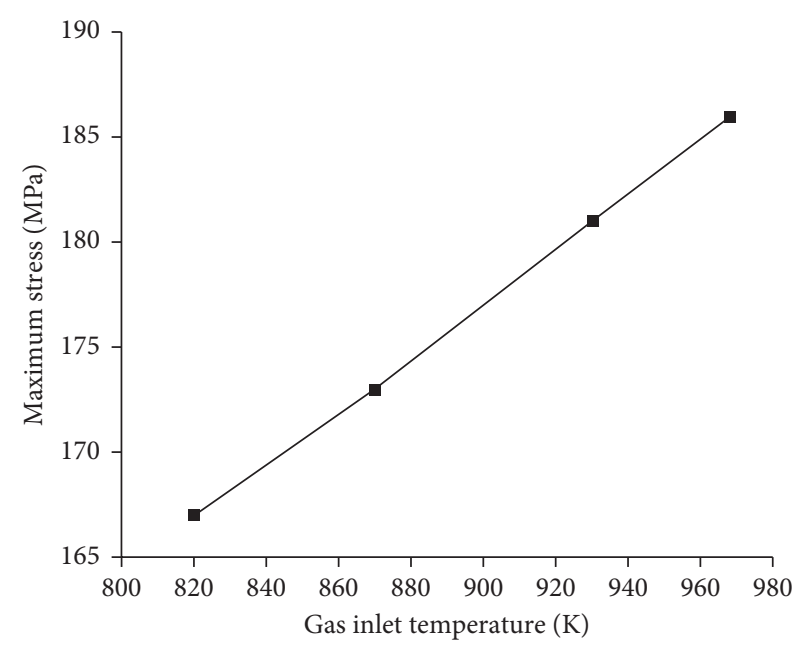

FIgURE 17: Maximum stress varies with temperature when gas inlet temperature is changed. 


\section{Conclusions}

(1) The maximum stress, strain, and deformation of air inlet and gas outlet side in recuperator are larger than those of air outlet and gas inlet side, when thermal stress is not taken into account and only pressure is taken into account. The result is the opposite when pressure and thermal stress are considered. Although the pressure ratio between the air outlet and the gas inlet of the recuperator is smaller than the pressure ratio between the air inlet and the gas outlet of the recuperator, the maximum stress, strain, and deformation of the air outlet and gas inlet side are obviously increased under the coupling effect of pressure and temperature. Therefore, the increase of thermal stress caused by the increase of temperature is remarkable and must be paid enough attention.

(2) The side of the gas passage is deformed to the air passage of the recuperator, the air passage becomes larger, and the gas passage decreases. The maximum deformation is smaller, which is in the order of $10^{-7} \mathrm{~m}$.

(3) With the increase of pressure ratio between air side and gas side, the maximum stress and maximum deformation of recuperator also increase. When the pressure ratio increases to 8.4, the maximum stress of the recuperator reaches $170 \mathrm{MPa}$ and reaches the strength limit of the heat exchanger material $0 \mathrm{Cr} 17 \mathrm{Ni} 12 \mathrm{Mo} 2$. Therefore, in order to ensure its safety and reliability when designing the heat exchanger, the pressure ratio between the air side and the gas side should not exceed 8.4.

(4) When gas outlet temperature and air outlet temperatures remain unchanged and the thermal ratio decreases, as the gas inlet temperature increases, the maximum stress increases. For every $50 \mathrm{~K}$ increase of gas inlet temperature, the maximum stress of recuperator increases by $2.3 \mathrm{MPa}$ and the maximum deformation increases by about $0.025 \mu \mathrm{m}$.

\section{Data Availability}

The data used to support the findings of this study are available from the corresponding author upon request.

\section{Conflicts of Interest}

The authors declare that they have no conflicts of interest.

\section{Acknowledgments}

The authors acknowledge the financial support provided by the Fundamental Research Funds for the Central Universities (grant no. 2018YZ02) and China University of Mining and Technology (Beijing) Program for Innovation and Entrepreneurship for Undergraduates (no. C202012154).

\section{References}

[1] W. Xi, J. Cai, and X. Huai, "Numerical investigation on fluidsolid coupled heat transfer with variable properties in crosswavy channels using half-wall thickness multi-periodic boundary conditions," International Journal of Heat and Mass Transfer, vol. 122, pp. 1040-1052, 2018.

[2] J. Cai, X. Huai, and W. Xi, “An optimal design approach for the annular involute-profile cross wavy primary surface recuperator in microturbine and an application case study," Energy, vol. 153, pp. 80-89, 2018.

[3] T. Y. Wu, Q. B. Yu, and T. Ma, "Numerical simulation on fluid flow and heat transfer performance in $\mathrm{CW}$ primary surface heat exchanger," Metallurgical Energy, vol. 36, no. S1, pp. 45-47, 2017.

[4] T. Ma, L.-X. Du, N. Sun, M. Zeng, B. Sundén, and Q.-W. Wang, "Experimental and numerical study on heat transfer and pressure drop performance of cross-wavy primary surface channel," Energy Conversion and Management, vol. 125, pp. 80-90, 2016.

[5] P. Maghsoudi, S. Sadeghi, H. Khanjarpanah, and H. H. Gorgani, "A comprehensive thermo-economic analysis, optimization and ranking of different micro turbine plate-fin recuperators designs employing similar and dissimilar fins on hot and cold sides with NSGA-II algorithm and DEA model," Applied Thermal Engineering, vol. 130, pp. 1090-1104, 2018.

[6] G. Xiao, T. Yang, H. Liu et al., "Recuperators for micro gas turbines: a review," Applied Energy, vol. 197, pp. 83-99, 2017.

[7] H. Liu and Z. Li, "The emerging micro-turbine technology," Power Engineering, vol. 21, no. 6, pp. 1532-1538, 2001.

[8] S. Moaveni, Finite Element Analysis - ANSYS Theory and Application, Beijing: Electronic Industry Press, Beijing, China, 2003.

[9] G. Wang, Practical Engineering Numerical Simulation Technology and its Practice on ANSYS, Northwest Polytechnic University Press, Xi'an, China, 1999.

[10] C. Zhang, ANSYS 8.0 Thermal Analysis Course and Case Study, Beijing; China Railway Publishing House, Beijing, China, 2005.

[11] D. Zhang and J. Wang, "Creep analysis of primary surface recuperator for micro gas turbines," Journal of Engineering Thermophysics, vol. 29, no. 4, pp. 671-673, 2008.

[12] X. Gui, "Analysis on three-dimensional flow and heat transfer in a cross wavy primary surface recuperator for a micro-gas turbine system," Journal of Engineering for Thermal Energy and Power, vol. 26, no. 5, pp. 518-522, 2011.

[13] D.-J. Zhang, J.-W. Wang, H.-X. Liang, M. L. Zeng, and Q. Wang, "Stress analysis of surface recuperator for micro gas turbine," Power Engineering, vol. 28, no. 2, pp. 200-204, 2008.

[14] E. Samaniego, C. Anitescu, S. Goswami et al., "An energy approach to the solution of partial differential equations in computational mechanics via machine learning: concepts, implementation and applications," Computer Methods in Applied Mechanics and Engineering, vol. 362, p. 112790, 2020.

[15] C. Anitescu, E. Atroshchenko, N. Alajlan, and T. Rabczuk, "Artificial neural network methods for the solution of second order boundary value problems," Computers, Materials \& Continua, vol. 59, no. 1, pp. 345-359, 2019.

[16] C. Rabczuk and C. Wang, Sequel to New Handbook of International Common Metal Materials, Beijing; Industrial Publishing House, Beijing, China, 1995.

[17] H. Liang and L. Du, "Experimental study on heat transfer resistance characteristics of primary surface recuperator," Journal of Engineering Thermophysics, vol. 30, no. 12, pp. 2110-2112, 2009. 